\title{
Sustaining the growth of library scholarly publishing in a New University Press
}

\author{
Graham Stone* \\ Jisc, UK \\ E-mail: graham.stone@jisc.ac.uk
}

\begin{abstract}
In 2012, the University of Huddersfield Press presented a paper at the 16th International Conference on Electronic Publishing on its new open access journals platform. At the time, the Press was one of the only New University Presses (NUP) in the UK and one of the first to publish open access journals, open access monographs and sound recordings. This article discusses a number of emerging business models for NUPs before developing Hahn's programme and publication level business plan, which is then related to the sustainability of the Press at Huddersfield. The article will demonstrate how the Press is able to show value to the University in order to secure funding. The paper will conclude with a discussion around the need for collaboration between library-led NUPs. Although this paper concentrates on the experiences of the University of Huddersfield Press, it will be relevant to other emerging or planned NUPs.
\end{abstract}

Keywords: Library, publishing, university press, open access, business models

\section{Introduction}

In 2012, the University of Huddersfield Press (the 'University Press') presented a paper at the 16th International Conference on Electronic Publishing on its new open access journals platform [39]. At the time, the Press was one of the only New University Presses (NUP) in the UK and one of the first to publish open access journals, open access monographs and sound recordings. Since then the Press has published seven journals, ten scholarly monographs and nine music recordings. However, over this time the University Press has developed organically without a clear business model.

This article will discuss a number of emerging business models that could be applied to NUPs before recommending a way forward for the University of Huddersfield Press. Hahn's [15] programme and publication level business planning will be described and expanded in relation to the sustainability of the University Press. The article will also demonstrate how the Press has been able to show value to the University in order to secure future funding.

Although this paper concentrates on the experiences of the University of Huddersfield Press, it will be relevant to other emerging or planned NUPs. These new publishing ventures, often based in the library, have harnessed the changes in the digital landscape and the rise of the open access movement to allow them to publish scholarly works, such as journals and monographs. Hahn [15] describes library publishing as offering a truncated list of services when compared to the traditional publishing model. These truncated services may in fact represent a leaner version of traditional 'legacy' publishers. Davis

\footnotetext{
*Previously University of Huddersfield.
} 
[8] sees these publishers as a 'dying industry' (p. 206), arguing that library scholarly publishing is able to 'step right into the tools that allow them to be effective 21st-century publishers' (p. 206).

The University of Huddersfield Press was re-launched in 2010 as a library led publishing initiative with decisions taken by an academic led Editorial Board. The principles governing the University of Huddersfield Press are that:

- All material published should be of high quality and peer reviewed.

- As a general rule, material should be published on Open Access via the University Repository, in order to maximise the potential for dissemination to as wide an audience as possible. Publications may also be made available by print-on-demand.

- The Press will operate on a cost recovery profit sharing model, with any profits being reinvested into the Press [43].

The library as publisher or library scholarly publishing is now a growing worldwide movement [37] and Huddersfield has followed the lead from NUPs in the United States, Australia and Germany [1, 25,46]. Since the launch of the Press at Huddersfield there are also a growing number of NUPs in the UK [23]. In 2016 there are now 17 university presses, including NUPs and established presses, such as Oxford, Cambridge, Manchester and Liverpool. In addition 12 universities are considering a NUP within the next 5 years. By 2020 there could be as many as 29 NUPs in the UK [19].

However, like Huddersfield, many NUPs have developed without a clear business model and plan. The American Research Libraries (ARL) and Association of American University Presses (AAUP) both concluded that business model development is an area that needs significant work [15,47].

It is important to define what is meant by the term 'business model' and 'sustainability' in relation to the University Press and this article. The definition of a business model is aligned with the Crossick report [6], which defines a business model as a series of workflows and processes that combine to produce books, journals or sound recordings, 'on an ongoing basis for a sizeable readership' [24, p. 5]. Esposito [12] questions the use of the term sustainability, preferring 'a strategy for economic viability'. However, even that term is not entirely appropriate to an open access university press, which does not seek to make a surplus. The University of Huddersfield Press is a not for profit venture. It is an exercise in scholarly communication of high quality, peer reviewed work. Esposito is correct in associating the term sustainability with that of maintainability or maintaining the status quo. The University Press does need to be sustainable by consolidating its position and acquiring stability within the University. However, the Press also needs to innovate in order to succeed. Therefore, use of the term sustainability is assumed to include both stability for the Press and the need to innovate and grow in order to achieve longer term viability.

\section{Business models}

In respect to the above definition of the term business model, the University Press does have workflows and process in place in order to publish high quality works. However, a business model as such is not well defined. There is currently no funding model and business plan in place. As such, the University Press operates on a project by project basis. Publications have relied on ad hoc funding from the University or external research funding, which has resulted in a strategy that is more emergent than deliberate [28]. A lack of deliberate strategy at a programme level is neither sustainable nor scalable. Therefore, despite the relative success of existing publications, the business model for Press publications on an 'ongoing basis' could be called into question. This is not an uncommon situation for NUPs. 
Table 1

Suggested business models [21,24]

\begin{tabular}{ll}
\hline Crossick report business models & \multicolumn{1}{c}{ Kwan's business models } \\
\hline Traditional publisher & Traditional publisher \\
New University Press & New University Press \\
Mission-oriented open access & Mission-oriented open access \\
Freemium open access & Author-pays model \\
Aggregator/distributor & Institutional subsidies to publisher's model \\
Author payment model & Third-party funding model \\
& Freemium open access \\
& Three-party (aka two-sided), market model \\
& Hybrid model \\
& Embargo model \\
& Advertising model \\
& Collaborative model \\
& SCOAP model \\
\hline
\end{tabular}

Regarding monograph business models, independent research commissioned by the Crossick Report identified six models $[6,24]$. However, the report also confirmed that 'there aren't many business models for OA monographs (publishing or aggregation)' and '[o]f those that do exist, many are relatively new and under development' [24, p. 7]. To a certain extent this could exonerate a NUP for a lack of strategy. Kwan [21] also discusses a number of similar models regarding open access publishing in general (pp. 69-74) (see Table 1).

Accepting that there is no one single model for publishing open access monographs and journals, and that none of the options are 'the best' frees the University Press up to experiment. London Economics [24] carried out theoretical tests of each model and established that each one has its own strengths, weaknesses, opportunities and threats. This SWOT analysis was taken further by the OAPEN-UK project [2] by suggesting a number of different groupings (see Table 2). A number of the more appropriate models regarding the University Press are discussed below.

\subsection{Author/Institution/Funder-pays models}

The institutional subsidy model within the Author/Institution/Funder-pays group best describes the business case for the University Press at present. The Press receives subsidies from the University, either centrally, from a School, a Research Centre or the Library, or from a funder on a publication by publication basis. Author or funder payment is also an option for non-University authors. However, this is on a project by project basis.

\subsection{Embargo/Delayed open access model}

In addition, the University Press operates an Embargo/Delayed open access model for one title. After print sales reduced the open access version was made available. However, it is not recommended that this model is followed in future as evidence points towards little advantage of embargoing open access version over print [14]. 
Table 2

Business models for open access monographs [2]

\begin{tabular}{ll}
\hline Groups & \multicolumn{1}{c}{ Models } \\
\hline Author/Institution/Funder-pays models & Publication fees/Book \\
& Processing Charges \\
& Institutional subsidies \\
Publisher/Press bears the risk revenue models & Toll-access/Print subsidy \\
& Freemium/Value added services to the reader \\
& Embargo/Delayed OA \\
& Cross Subsidies \\
& Endowments \\
& Fundraising \\
& Advertising \\
& Collaborative underwriting \\
Community-pays models & Commissioning \\
& Crowdfunding \\
& Liberation OA \\
& Freemium community \\
\hline
\end{tabular}

\subsection{Freemium model}

There is also an element of the Freemium model to University Press publications. This applies specifically to monographs, which are published in both print and electronic form to satisfy the needs of researchers [26]. At present the Press makes the PDF version available on open access, with print on demand copies for purchase [21,27]. Hahn [15] concluded that this model was probably not capable of supporting the whole publishing process, therefore a particular funding model would be required. This is where the Institution/Funder-pays model described above makes sense as the way forward for the University Press as the main business model and this is discussed further below.

\section{Sustainability and scalability}

The lack of a formal business model for the University Press has had an effect on sustainability, scalability and funding. Many new presses have paid little attention to sustainability and financial planning [7]. In a survey for ARL, Hahn [15] found that very few library publishers were able to 'support even 10 journal titles or more than a handful of monographic works' (p. 25).

If the University Press wishes to expand it has to identify the additional resources it needs and this is a long-term commitment. Without sufficient funding this could effectively divert resources from other areas [48]. This leads to the question of scalability. For example, the library at Georgia Institute of Technology hesitated in more aggressive marketing of its press due to fears that this could generate more demand than the press could satisfy [31]. Essentially the press becomes a victim of its own success. Bryn Geffert, librarian and director of the NUP at Amherst College gives sage advice, "[w]e want to do a few things well, not overextend" [18]. The University of Huddersfield Press is approaching this stage of maturity. A more successful Press means that the library needs to reallocate already precious staffing resources or new resources must be identified.

The adoption of the Institution/Funder-pays model described above allows for a more focused funding model to be developed as part of a more strategic programme level plan. This in turn should lead to 
greater sustainability and business planning. Hahn [15] suggests two levels of business plans for library publishers; programme level planning and publication level planning:

'[T]wo levels of business planning are evident in library publishing services: publication-level planning and program-level planning. Most commonly, when an individual publication generates revenue it supplements broader program support for the publication rather than entirely covering service costs. ... Most library publishing services rely heavily on program-level funding and revenue from individual titles provides only a modest supplement to this support' [15, p. 18].

\section{Programme level planning}

Although open access business models for NUPs have been at an embryonic stage for the last five to ten years, without a business model, the University Press is unable to formulate a business plan. This results in the Press continuing to operate at publication level where funding decisions are made on a case by case basis with no overall programme strategy for publications. However, if the Press is to expand its publication plans to publish more output, a more formal model is required. Looking to the future, staffing and funding challenges need to be resolved in order for the Press to be sustainable. Planning is needed at both programme level and publication level in order for the initiative to continue its success.

\subsection{Staffing}

Staffing needs consideration as part of programme level planning. Many library publishing initiatives take on open access publishing without any increase in staff. The effect of increased success versus a limited staff base has been the focus of discussion for many successful presses. For, example, open access publishing at the University of South Florida (USF) was established in 2007 with no increase in staff [33]. The Center for Digital Research and Scholarship, Columbia University (CRDS) cites staffing as the reason for only being able to take on a limited number of journals every year [33]. Mullins et al. [31] in a study conducted between 2010 and 2011 found similar figures. The number of staff allocated to publishing activities ranges between 0.9-2.4 FTE. Staff dedicated to library publishing programmes are described as relatively rare. Georgia Institute of Technology operated on an informal basis for its first five years, with staff funded from the library's standing budget [31].

This is a crucial step in identifying a manageable workflow in order to ensure that too much is not taken on $[15,20]$. In order for the Press at Huddersfield to grow, the library either needs to reallocate staffing resources from the library or identify new resources. With no increase in staffing, if the number of publications increases as the University Press gains prestige there is clearly a sustainability issue.

Examples of expansion in order to sustain growth are also evident. In 2011, USF recruited two fulltime staff positions, with 0.5 FTE from each position working on the additional workload from the expansion of USF journals [33]. In 2007, the University of Illinois at Chicago (UIC) Library requested $\$ 100,000$ for a full-time Digital Publishing Librarian and a half-time programmer. Without this investment in staff, the library reasoned that Journals@UIC would have to be very selective when taking on new projects [4, p. 14]. The University of Pittsburgh Press employed 3.05 FTE for its journals operations alone, all from internal reallocation of the operating budget. This has helped Pittsburgh to grow to 35 open access journals in six years [9].

A proposal for a new post of publications and marketing manager at the University of Huddersfield Press has been suggested as part of a sustainability report. This post allows for better engagement with authors [10] and gives the Press an editorial function that it currently does not have. Thatcher quoted 
in Skinner et al., describes the editorial function as 'the key to all of this: that's what makes this publishing' [38]. This would allow the Press to have better control over publications and to identify new opportunities [30].

\subsection{Funding models}

As discussed above, the lack of a formal business model for the University Press has meant that there is no funding model at programme level. Currently the Press states on its web pages that it operates, 'on a cost recovery profit sharing model, with any profits being reinvested into the Press' [43]. However, a report from Ithaka [3] on university presses in the United States found that,

'The cost recovery model of presses has become one major constraint. One librarian commented that "presses are trapped in the cage of 'What can I do to make money?' and they have so few resources to climb out of that cage. They are like hamsters scrabbling along and pushing their little wheels." They are caught in a "catch 22", where they lack room for experimentation because their budgets are so tight, and thus cannot inspire interest in their administrators to fund anything new' (p. 19).

Furthermore, a business model based on scholarly communication rather than profitability, but working on a cost recovery model appears to be contradictory. The cost recovery model is closer to the Freemium model, which, as Hahn [15] states, is not sustainable for the Press as the only funding model. The Institution/Funder-pays model is the more appropriate model. However, this in itself does not guarantee the funding in order to support the model. In order to adopt programme level planning, the funding process has to be planned too.

The funding behind the Institution/Funder-pays model needs to be a mixed approach, which would include the following:

- A contribution from the library. However, as the only source of funding, this is unsustainable in the long term if the Press is going to grow its publications. Library funding was effectively where the ARL libraries were in 2007. Hahn concludes that, "[t]here is a solid base of support within the library budget, but for real growth to meet existing and emerging demands for publishing services, many institutions see that additional support from campus administration will be necessary' [15, p. 27].

- Contributions from the University. This would include dedicated resources in order to publish an agreed number of publications a year, such as start-up journals, monographs and recordings. An existing example of this is the Purdue model, which aligns itself closely with the strategy of the University [31].

- Contributions from research funders. A number of University Press monographs have already been financed from funders such as the Heritage Lottery Fund and Leverhulme Trust. The journals platform itself was developed as a result of Jisc funding [39]. This would need to be costed at the time of grant application, in which case there needs to be collaboration between the Press and the pre-awards office in the Research and Enterprise Directorate at Huddersfield. As such, this funding falls outside of the publication level process, as funding would be on a publication-by-publication basis. However, many funders are not averse to this approach [5]. In order for this to be effective, a set of guidelines would need to be produced. In the medium to long term, revisions to the bidding processes could increase publications when using this method of funding.

The adoption of the institution/funder pays model also goes some way to eradicate 'acceptable loss' including the absorption of staffing and other costs into the library budget if no sales income is received [41]. 
In addition to the Institution/Funder pays business model, the Press also has the option to use a fee based model for external publications [31,42]. However, the York Digital Journals (YDJ) initiative felt that the enforcement of a hosting fee for external journals was a barrier, due to the way humanities and social sciences research is funded [20]. Again, this model may work on an ad hoc basis, but does not need to form part of the business model.

Contributions from the University as part of the Institution/Funder pays model is perhaps the key to both sustainability and innovation for the University Press. However, one of the issues with University funding is that mention of publishing is associated with profitability of commercial presses, rather than a not for profit or cost recovery model of scholarly publishing.

In 2015, a sustainability paper was taken to the University Press Editorial Board. In addition to the above discussion on programme level planning and the need for sustainability through robust funding models. It provided a five year cash flow and profit forecast based on growth by two journals a year, and two monographs to be published in 2016, increasing to five a year by 2019. The forecast also included recurrent costs, such as marketing budgets, memberships etc. Using the Institution/Funder-pays model and ignoring any potential sales figures (which are by no means guaranteed), a modest investment by the University of $£ 15 \mathrm{~K}$ in 2016 , rising to $£ 30 \mathrm{~K}$ in 2019 would completely cover non staffing costs, with any surplus from sales used to publish additional content. Figures are based on known costs for journal publications, which incur a one off set up cost of around $£ 750$. Monographs are estimated at $£ 4,000$ for up to 100,000 words and are similar to other NUPs estimates [42]. Recurrent costs such as membership are estimated at $£ 3,000$. Additional income from sales would also be possible, but on a very small scale. For example, an open access monograph would also have 100 print on demand copies produced. If 70 copies were sold at approximately $£ 25$ per copy, this would generate a surplus of $£ 1,750$. This surplus could then be used for marketing and recurrent expenditure for the Press.

The Institution/Funder pays business model allows for a fee waiver model for peer reviewed publications. In addition to the investment by the University, the library proposed that it increased staffing to $£ 40 \mathrm{~K}$, which would include a new 0.6 FTE post of Marketing and Publications Manager (described above), in addition to 0.2FTE from the post of Collections and Scholarly Communications Librarian, which manages the University Press.

However, in order to justify an investment of $£ 15-30 \mathrm{~K}$ per year, the case for value must be made to the University.

\section{Assessing the value of the Press}

The justification of reputational value is an important argument for a Press that does not seek to turn a profit. The argument here is not how much a print run of 100 books will make in profit (clearly there is no profit unless the books are sold at vastly inflated prices), but how much reputational value and benefit there is to the University in publishing an output on open access. An output that may well not get published by a commercial press.

The re-launch of the University Press in 2010 has put the Press in a strong position to show value. The Press was able to submit published output to the 2014 Research Excellence Framework (REF) [35]. The outputs were submitted to the Unit of Assessment (UoA) covering the Music, Drama, Dance and Performing Arts Unit of Assessment (UoA 35) [36]. This UoA was also by far the most successful UOA in Huddersfield's REF2014 submission [44].

The UoA 35 submission consisted of 21 staff (17.5 FTE) and 100 research outputs. University of Huddersfield Press publications were included in 11 outputs (some of these were portfolios, which consisted 
of more than one output). Therefore, $11 \%$ of the outputs were associated with Press publications. While REF scores cannot be associated with individual outputs, $85 \%$ of music research at Huddersfield was judged to be Internationally Excellent ( $3 *$ and $4 *$ ). $44 \%$ of the overall submission ranked as 'WorldLeading' ( $4 *)$. It is not unreasonable to suggest that a number of Press publications were rated as $4 *$ and $3 *$ outputs. In addition to the individual outputs, all of the publications and releases contributed to the environment and impact statements.

Where this becomes relevant to the reputational value of the Press to the University is when the HEFCE quality-related research funding (QR funding) is taken into account. The 2015-2016 funding was determined using the REF [17]. Six outputs from the Press (three CDs and three books) contributed to $11 \%$ of the Schools REF output (they were submitted more than once by a number of authors). Assuming they matched the average UoA profile, it is possible to calculate the average QR income per output. One title, Shibusa: extracting beauty, a book entirely funded by the Leverhume Press has brought in $£ 7.5 \mathrm{~K}$ of funding in 2015-16. Another, Noise In and As Music, a title paid for by the School out of research funds has generated nearly eight times its publishing costs in QR funding. Both titles were available as open access monographs and at least one title would not have been published in time for the REF (or at all) had it been submitted to a commercial publisher.

The value proposition to the University is clear. If this is the benefit to research income from just one UoA and just one Department within the University, what would be the contribution of Press publications in other research areas if they were appropriately funded by the University? Compared to the potential to return a sizeable amount of QR funding through just one Department, the sum of $£ 15 \mathrm{~K}$ to cover all Press output across a number of disciplines and UoAs in 2016 seems modest. It also amounts to just nine gold open access journals articles [34]. It seems plausible that if the Press were funded in this way it could adopt a similar approach to ANU Press using the Press Board as part of the proposal approval process before peer review [29].

Before the REF2014, Lawson [22] observed that it was 'too early to say whether any existing UK library publishing services have had an affect on their institution's reputation' (p. 45). However, this article argues that the University Press is able to demonstrate reputational value to the University and that this justifies a local subsidy [7,16]. A relatively small investment (as opposed to subsidy, which implies little or no return) from the University could help to make the Press sustainable in the short term and also to help it grow and innovate in the long term. As a result, outputs for the post-2014 REF may be significantly increased under an Institution/Funder pays model.

A programme level planning model would help to develop a publishing policy, which would in turn help to develop publication level planning; the what, how and why of the publishing process [30]. The Press has a golden opportunity to define a set of targeted publications around the post-2014 REF. Furthermore, programme level planning will result in adequate and sustained staffing and funding in the long term [13]. Without this level of planning, the Press would continue to exist on a publication by publication basis.

\section{Publication level planning}

The Press has been operating at publication level since its re-launch in 2010. It has developed organically from lessons learned after each new publication. However, without an overarching programme level plan the Press has been unable to develop a defined strategy. There are still significant gaps in the publication level planning process. In order for publication level planning to work, programme level 
planning needs to be in place. For example, planning at the programme level results in a business plan. This plan can outline the case for growth of the Press. As described above, the plan suggests a more robust funding allocation and modest increase in staffing. This in turn supports a greater number of publications and improved publication level planning. An annual plan for each journal title as well as the Press itself, which includes a budget, key dates and an evaluation process, can then be produced.

An example of where publication planning is already working at Huddersfield is for Fields: Journal of Huddersfield Student Research [40]. The Press has worked with the University's Teaching and Learning Institute to ring-fence funding for the journal. Publication level planning helps to address issues that have arisen in the process, such as budget, key dates and the evaluation process. Launched in 2015, the journal is now entering its third year of publication and lessons learned from volume 1 have led to a revision in the notes for contributors, a writing retreat and conference attendance for student authors and marketing around campus.

Programme level planning and stability in funding would allow annual planning to be rolled out for all publications.

\section{Collaboration}

The Press has achieved a great deal in five years. It is only with a strong portfolio of publications that a business model can be chosen with confidence. However, the growth of NUPs is also happening at the same time as a move towards shared services. Mullins et al. [31] recommended in their report to SPARC that collaborations should be used to 'leverage resources within campuses, across institutions, and between university presses, scholarly societies, and other partners' (p. 19). There is a long tradition of collaboration between university presses and partners outside of presses' core competencies [47]. The Ithaka Report University publishing in a digital age [3] suggested that a collaborative technology platform is the way forward for university presses. Since then, the launch of OAPEN and DOAB has meant that NUPs can have their work published and distributed through these platforms.

However, further research is required within the UK as new presses emerge. In October 2014, an exploratory meeting between library directors in the Northern Collaboration [32], a group of 25 higher education libraries in the north of England was held to discuss possible collaboration and shared services relating to university presses and potential library publishing ventures. As a result of this meeting, a research project has now been funded by Jisc in order to understand the landscape relating to existing and planned NUPs in the UK in order to:

- Identify existing and future new university presses in the UK.

- Learn of the motivations behind their establishment.

- Determine the types of output being published.

- Gather information on governance and policies.

- Identify the publishing platforms being utilised.

- Ascertain what business models are being applied.

- Identify workarounds, gaps and frustrations in the workflows.

Early findings were reported at the 2016 LIBER conference [19] and a report is due to follow.

Collaboration will help to achieve best practice amongst NUPs and this will further enhance programme and publication level planning by creating efficiencies through shared practice. In addition, this 
may also be achieved through the building of a library publishing coalition such as the Library Publishing Coalition in the United States [11]. Potentially a UK/European LPC conference could be planned as well as a landscape survey for other European countries.

\section{Conclusion}

In 2012, the Deans of Libraries at Purdue, Georgia Institute of Technology and Utah University were convinced by the evidence put forward to them that there is a demand for library scholarly publishing services and that decisions needed to be made in order to 'foster and continue this work' [31, p. 2]. Watkinson suggests that 'a quieter revolution was in fact taking place, more accurately attuned to the real needs of scholars and other campus communities' [45]. In the UK, institutions such as UCL, Cardiff and the White Rose universities see that the time has now come to support library publishing in the UK [23].

This article has shown that the addition of programme and publication level planning and a commitment to a business model allowing a deliberate strategy to be put in place [28] will enrich the University of Huddersfield Press, which is ideally placed to be a leading NUP in the UK. This in turn will add to the reputational value of the University.

\section{References}

[1] M. Bargheer and J. Pabst, 'being small is not a fault': Making sense of the newer generation of German-language university presses, Learned Publishing 29(S1) (2016), 335-341. doi:10.1002/leap.1053. [Accessed 24 October 2016].

[2] D. Beech and C. Milloy, Business models for open access monographs: A summary document, Available from http://oapen-uk.jiscebooks.org/files/2015/04/Annex-A-OAPEN-UK-Business-Models-SWOT-Workshop-preparatorydocument.docx [Accessed 23 October 2016].

[3] L. Brown, R. Griffiths and M. Rascoff, University Publishing in a Digital Age, Ithaka, New York, NY, 2007. Available from: http://www.sr.ithaka.org/wp-content/uploads/2015/08/4.13.1.pdf [Accessed 23 October 2016].

[4] M.M. Case and N.R. John, Publishing journals@UIC, ARL 252/253 (2007), 12-15. Available from: http://old.arl.org/ bm doc/arl-br-252-253-uic.pdf [Accessed 23 October 2016].

[5] E. Collins, C. Milloy and G. Stone, Guide to Open Access Monograph Publishing for Arts, Humanities and Social Science Researchers, AHRC/Jisc Collections, London, 2015. doi:10.5920/oapen-uk/oaguide. [Accessed 23 October 2016].

[6] G. Crossick, Monographs and Open Access: A Report to HEFCE, HEFCE, London, 2015. Available from http://www. hefce.ac.uk/pubs/rereports/year/2015/monographs/ [Accessed 23 October 2016].

[7] R. Crow, Campus-Based Publishing Partnerships: A Guide to Critical Issues, SPARC, Washington, DC, 2009. Available from: http://www.sparc.arl.org/sites/default/files/pub_partnerships_v1.pdf [Accessed 23 October 2016].

[8] M. Davis, Doing well by doing good: How libraries can reclaim their role at the center of the information universe, Insights 26(2) (2013), 204-209. doi:10.1629/2048-7754.92. [Accessed 23 October 2016].

[9] T.S. Deliyannides, The library as publisher: University library system, University of Pittsburgh, in: PALCI Member Meeting, June 12-13, 2013, Bethlehem, PA. Available from: http://d-scholarship.pitt.edu/19048/ [Accessed 23 October 2016].

[10] P.J. Dougherty, Reimagining the university press: A checklist for scholarly publishers, Journal of Electronic Publishing 13(2) (2010). doi:10.3998/3336451.0013.202. [Accessed 23 October 2016].

[11] Educopia Institute, Library Publishing Coalition. Available from: http://librarypublishing.org/ [Accessed 23 October 2016].

[12] J.J. Esposito, Stage five book publishing, Journal of Electronic Publishing 13(2) (2010). doi:10.3998/3336451.0013.204. [Accessed 23 October 2016].

[13] J.J. Esposito, Creating a new university press, The Scholarly Kitchen, Weblog. Available from: http://scholarlykitchen. sspnet.org/2011/05/25/creating-a-new-university-press-the-first-of-a-two-part-post/ [Accessed 23 October 2016].

[14] E. Ferwerda, R. Snijder and J. Adema, OAPEN-NL a Project Exploring Open Access Monograph Publishing in the Netherlands: Final Report, OAPEN, The Hague, 2013. Available from: https://www.surf.nl/binaries/content/assets/surf/ en/knowledgebase/2013/OAPEN+Rapport_+A+project+exploring+Open+Access+monograph+publishing+in+the+ Netherlands_22102013.pdf [Accessed 23 October 2016]. 
[15] K.L. Hahn, Research Library Publishing Services: New Options for University Publishing, Association of Research Libraries, Washington, DC, 2008. Available from http://www.arl.org/storage/documents/publications/research-librarypublishing-services-mar08.pdf [Accessed 23 October 2016].

[16] C. Harboe-Ree, Just advanced librarianship: The role of academic libraries as publishers, Australian Academic \& Research Libraries 38(1) (2007), 15-25. doi:10.1080/00048623.2007.10721264. [Accessed 23 October 2016].

[17] Higher Education Funding Council for England, How We Fund Research. Available from: http://www.hefce.ac.uk/rsrch/ funding/mainstream/ [Accessed 23 October 2016].

[18] J. Howard, For new ideas in scholarly publishing, look to the library, Chronicle of Higher Education 4 February 2013. Available from: http://chronicle.com/article/Hot-Off-the-Library-Press/136973/ [Accessed 23 October 2016].

[19] C. Keene, C. Milloy, V. Weigert and G. Stone, The rise of the New University Press: The current landscape and future directions. in: LIBER Annual Conference, 29th June-1st July 2016, Helsinki, Finland. Available from http://eprints.hud. ac.uk/28989/ [Accessed 23 October 2016].

[20] A. Kosavic, The York Digital Journals Project: Strategies for institutional open journal systems implementations, College \& Research Libraries 71(4) (2010), 310-321. doi:10.5860/crl-36r1. [Accessed 23 October 2016].

[21] A. Kwan, Open access and scholarly monographs in Canada, Masters dissertation, Simon Fraser University, Vancouver, 2011. Available from http://publishing.sfu.ca/2013/08/open-access-and-scholarly-monographs-in-canada/ [Accessed 23 October 2016].

[22] S. Lawson, Library publishing services: An investigation into open access publishing in academic libraries, Masters dissertation, University of Brighton, Brighton, 2013. doi:10.6084/m9.figshare.805214. [Accessed 23 October 2016].

[23] A. Lockett and L. Speicher, New university presses in the UK: Accessing a mission, Learned Publishing 29(S1) (2016), 320-329. doi:10.1002/leap.1049. [Accessed 24 October 2016].

[24] London Economics, Economic Analysis of Business Models for Open Access Monographs: Annex 4 to the Report of the HEFCE Monographs and Open Access Project, HEFCE, London, 2015. Available from http://www.hefce.ac. uk/media/hefce/content/pubs/indirreports/2015/Monographs, and,open, access/2014_monographs4.pdf [Accessed 23 October 2016].

[25] C. Lynch, Imagining a university press system to support scholarship in the digital age, Journal of Electronic Publishing 13(2) (2010). doi:10.3998/3336451.0013.207. [Accessed 23 October 2016].

[26] C. Milloy and E. Collins, Researcher Survey 2014: Survey of Use of Monographs by Academics - as Authors and Readers, Jisc, London, 2014. Available from http://oapen-uk.jiscebooks.org/files/2012/02/OAPEN-UK-researcher-survey-final. pdf [Accessed 23 October 2016].

[27] C. Milloy and E. Ferwerda, Open Access Monographs in the Humanities and Social Sciences Conference. Jisc Collections, OAPEN, London, The Hague, 2013. Available from: http://oapen.org/download?type=export\&export=oa_monographs_ conference_report_oct13 [Accessed 23 October 2016].

[28] H. Mintzberg and J.A. Waters, Of strategies, deliberate and emergent, Strategic Management Journal 6(3) (1985), 257272. doi:10.1002/smj.4250060306. [Accessed 23 October 2016].

[29] R. Missingham and L. Kanellopoulos, University presses in libraries: Potential for successful marriages, OCLC Systems \& Services: International Digital Library Perspectives 30(3) (2014), 158-166 doi:10.1108/OCLC-01-2014-0001. [Accessed 23 October 2016].

[30] S. Morris, E. Barnas, D. LaFrenier and M. Reich, The Handbook of Journal Publishing, Cambridge University Press, Cambridge, 2013. doi:10.1017/CBO9781139107860. [Accessed 23 October 2016].

[31] J.L. Mullins, C. Murray Rust, J.L. Ogburn, R. Crow, O. Ivins, A. Mower, D. Nesdill, M. Newton, J. Speer and C. Watkinson, Library Publishing Services: Strategies for Success. Final Research Report, SPARC, Washington, DC, 2012. Available from: http://docs.lib.purdue.edu/purduepress_ebooks/24/ [Accessed 23 October 2016].

[32] Northern Collaboration, The Northern Collaboration. Available from: http://www.northerncollaboration.org.uk/ [Accessed 23 October 2016].

[33] A.M. Perry, C.A. Borchert, T.S. Deliyannides, A. Kosavic, R. Kennison and S. Dyas-Correia, Libraries as journal publishers, Serials Review 37(3) (2011), 196-204. doi:10.1016/j.serrev.2011.06.006. [Accessed 23 October 2016].

[34] S. Pinfield, J. Salter and P.A. Bath, The 'total cost of publication' in a hybrid open-access environment: Institutional approaches to funding journal article-processing charges in combination with subscriptions, Journal of the Association of Information Science and Technology 67(7) (2016), 1751-1766. doi:10.1002/asi.23446. [Accessed 23 October 2016].

[35] Research Excellence Framework, REF2014, Available from: http://www.ref.ac.uk/ [Accessed 24 October 2016].

[36] Research Excellence Framework, UoA 35 Music, Drama, Dance and Performing Arts, University of Huddersfield, Available from: http://results.ref.ac.uk/Results/BySubmission/2521 [Accessed 23 October 2016].

[37] C.N. Simser, M.G. Stockham and E. Turtle, Libraries as publishers: A winning combination, OCLC Systems \& Services: International Digital Library Perspectives 31(2) (2015), 69-75. doi:10.1108/OCLC-01-2014-0006. [Accessed 23 October 2016].

[38] K. Skinner, S. Lippincott, J. Speer and T.O. Walters, Library-as-publisher: Capacity building for the library publishing subfield, Journal of Electronic Publishing 17(2) (2014). doi:10.3998/3336451.0017.207. [Accessed 23 October 2016]. 
[39] G. Stone, Huddersfield open access publishing, Information Services and Use 31(3-4) (2011), 215-223. doi:10.3233/ ISU-2012-0651. [Accessed 23 October 2016].

[40] G. Stone, K. Jensen and M. Beech, Publishing undergraduate research: Linking teaching and research through a dedicated peer reviewed open access journal, Journal of Scholarly Publishing 47(2) (2016), 147-170. doi:10.3138/jsp.47.2.147. [Accessed 23 October 2016].

[41] The Association of American University Presses, Press and library collaboration survey, Available from: http://www. aaupnet.org/images/stories/data/librarypresscollaboration_report_corrected.pdf [Accessed 23 October 2016].

[42] University College London, Publish with UCL Press, Available from: https://www.ucl.ac.uk/ucl-press/publish [Accessed 23 October 2016].

[43] University of Huddersfield, University of Huddersfield Press: About Us, Available from: http://unipress.hud.ac.uk/about, us/ [Accessed 23 October 2016].

[44] University of Huddersfield, Research Excellence Framework 2014. Available from: http://www.hud.ac.uk/ref2014/ [Accessed 23 October 2016].

[45] C. Watkinson, The university as publisher revisited, Insights 27(2) (2014), 181-185. doi:10.1629/2048-7754.131. [Accessed 23 October 2016].

[46] C. Watkinson, Why marriage matters: A North American perspective on press/library partnerships, Learned Publishing 29(S1) (2016), 342-347. doi:10.1002/leap.1044. [Accessed 24 October 2016].

[47] L. Withey, S. Cohn, E. Faran, M. Jensen, G. Kiely, W. Underwood, B. Wilcox, R. Brown, P. Givler, A. Holzman and K. Keane, Sustaining scholarly publishing: New business models for university presses: A report of the AAUP task force on economic models for scholarly publishing, Journal of Scholarly Publishing 42(4) (2011), 397-441. doi:10.1353/ scp.2011.0035. [Accessed 23 October 2016].

[48] J. Xia, Library publishing as a new model of scholarly communication, Journal of Scholarly Publishing 40(4) (2009), 370-383. doi:10.3138/jsp.40.4.370. [Accessed 23 October 2016]. 